\title{
Sensitivity Analysis of the Thermal Energy Need of a Residential Building Assessed by means of the EN ISO 52016 Simplified Dynamic Method.
}

\author{
Franz Bianco Mauthe Degerfeld ${ }^{1,}$, , Ilaria Ballarini ${ }^{1}$, Giovanna De Luca ${ }^{1}$, Mamak P. \\ Tootkaboni ${ }^{1}$ and Vincenzo Corrado ${ }^{1}$ \\ ${ }^{1}$ Dipartimento Energia, Politecnico di Torino, Torino, Italy
}

\begin{abstract}
The EN ISO 52016-1:2018 technical standard has introduced a new simplified dynamic method for the calculation of the building energy need for heating and cooling. This new procedure combines a low amount of input data required, as for the previous quasi-steady and dynamic simplified methods of the withdrawn EN ISO 13790 standard, with an increased accuracy, which would reduce the gap with detailed dynamic methods. This work is part of a broader research activity aimed at investigating the new simplified dynamic model and highlighting its strengths and weaknesses, in terms of accuracy and robustness. Specifically, the work addresses the parameters that have a great influence on the final results and the effects of uncertainties in input data. To this purpose both standard and tailored energy performance assessments have been applied, in particular in the first one a continuous operation period of the space heating system was supposed, and in the second one an intermittent operation system was chosen. A sensitivity analysis was also carried out to quantify the variation of the heating and cooling loads with the set-point temperature, the windows physical properties, the heat capacity and the thermal transmission properties of opaque components, as well as the occupancy related input parameters, such as the internal heat gains and the ventilation flow rate. The analysis was applied to a multi-unit residential building located in Rome and built in the first half of the 20th century. The results outline absolute relevance of the set point temperatures. The significance of occupant behaviour and the importance of the correct definition of the component thermal properties is also pointed out through the comparison between the standard and tailored assessments.
\end{abstract}

\section{Introduction}

In 2018, the new EN ISO 52016-1 standard [1] was published. It presents new models for the calculation of the energy performance of buildings, replacing those presented ten years earlier in EN ISO 13790 [2]. The purpose of the previous standard was to present a procedure capable of combining a moderate complexity and precision of the input data with a good ability to predict the real behaviour of the building. In the new standard, besides a quasi-

\footnotetext{
Corresponding author: franz.bianco@polito.it
} 
steady-state calculation model, which is not much different from the EN ISO 13790 one, a simplified dynamic calculation model was presented. The focus will be on the latter, which presents several differences compared to the model provided by EN ISO 13790, specifically referred to a different modelling of the building thermal inertia. Although there is a growing body of literature that compares different methods for the buildings energy performance calculation, the use of new EN ISO 52016-1 hourly method has not been sufficiently investigated yet. The majority of these comparative studies analyse in-depth the conditions and purposes for which a simplified calculation model can estimate the energy performance of the building with a sufficient level of accuracy when compared with a detailed numerical simulation model.

Several studies conducted on the monthly quasi-steady method of EN ISO 13790, such as the work of Ballarini et al. [3], showed that this method typically overestimates the thermal losses, compared with dynamic models, and presents several limitations to assess the thermal energy need in intermediate periods (i.e. spring and autumn). This type of error was also discussed by Jokislao and Kurnitski [4] for the calculation of the monthly utilization factor of the heat gains, showing strong deviations between night and day heat demand compared to a dynamic simulation model, especially for light-weighted building structure. Besides, other studies pointed out that the mismatch between models can also be originated by the different ways used to define the thermal losses of the building envelope, thus the importance of a correct evaluation of the heat transfer coefficient, underlined by Corrado and Fabrizio [5], and the issue of using the indoor operative temperature or the indoor air temperature, as in the study of Gasparella and Pernigotto [6]. Many authors highlighted the noticeable deviation between the calculation models; in particular Kokogiannakis et al. [7] pointed out the large differences that occur for heating intermittent cases. For this reason, several works such as Corrado et al. [8] and Beccali et al. [9], suggested that a dynamic simplified method would be preferable to a quasi-steady one.

The EN ISO 13790 simplified dynamic method was also analysed in-depth in many research works which showed that, although it is based on a much smaller number of input data compared to a detailed dynamic calculation method, the simplified hourly method lead to results closer to a dynamic simulation model than to a stationary method [10]. Atmaca et al. [11] investigated the deviations that exist between the simplified hourly method and a detailed dynamic simulation (EnergyPlus) in determining the heating energy needs, by varying the thermal mass of the building. The analysis, developed for an apartment with five different types of external walls, confirmed that the simplified hourly method can be reliable in modelling the thermal capacity of the buildings that are not very complex. The general reliability of the hourly model of the EN ISO 13790 standard was also confirmed in a study conducted by Costantino et al. [12] by estimating the heating and cooling thermal needs of a building for zootechnical shelter. The results, compared with the ones from a detailed dynamic simulation, showed slight deviations due to the different assessment of the thermal capacity in the two calculation methods.

Up to now, few studies have investigated the new EN ISO 52016-1 standard method accuracy. Preliminary results were achieved by Ballarini et al. [13], by comparing the new hourly method with the old EN ISO 13790 model and a detailed dynamic simulation model (EnergyPlus). The analysis was aimed at understanding whether the new hourly model could represent a good compromise between the easiness of application - typical of a simplified calculation method - and the accuracy of the results - characteristic of a detailed dynamic calculation. Considering the limitation due to the case study presented, i.e. a standard plan of a single-family house, the results showed that the hourly method of EN ISO 52016-1, with appropriately detailed input data, provides results closer to the outputs of the detailed dynamic simulation in comparison to the hourly method of EN ISO 13790, especially concerning heating and cooling thermal loads. Although both simplified methods 
demonstrated to provide a valid estimation of the building's thermal needs, there are significant deviations between the thermal time constants obtained by applying the various calculation methods. Furthermore, the new standard was compared with the TRNSYS model for six BESTEST cases by Siva Kamaraj [14], for lightweight and heavyweight classes of construction with free-floating, continuous, and intermittent HVAC system control strategies. As the simulations were run for a wide range of buildings and different weather files, including Milan (Italy), Palermo (Italy), Denver (USA), and Colorado (USA), results showed a range of deviation between $10 \%$ and $30 \%$ in the heating needs, and between $25 \%$ and $40 \%$ in cooling needs.

Due to the deficiency of the analysis currently done on the EN ISO 52016-1 simplified dynamic calculation method, it is recommended to evaluate the accuracy, robustness, flexibility, transparency, and reproducibility of the model. The present paper represents a first step in the process of EN ISO 52016-1 validation, aimed at the definition of the different weights that input parameters have in the calculation of the energy performance of buildings. This study was carried out by analysing the sensitivity of energy needs and the loads for the heating and cooling season to different input parameters, such as the set-point temperature, the window physical properties, the thermal capacity of the opaque building components, etc. A residential building located in Rome, Italy, was selected as a case study, and both standard and tailored energy performance assessments were applied. The main features of the simplified dynamic calculation of EN ISO 52016, the boundary conditions, and the other assumptions were studied in detail, as to reach a holistic analysis.

\section{Methodology}

As introduced, a case-study approach was used to facilitate the achievement of the research goals. The methodology applied is based on a sensitivity analysis on the thermal behaviour of the case-study aimed at evaluating at what extent different input parameters influence the output results. In the following paragraphs, the calculation model, the sensitivity analysis methodology, the case study and the modelling assumptions and simplifications are described in detail.

\subsection{Description of the calculation model (EN ISO 52016-1)}

The simplified dynamic calculation model of the EN ISO 52016-1 standard is applicable to evaluate on an hourly basis the sensible thermal load for space heating and cooling, the latent load for the (de-)humidification, the internal temperature (operative, air and / or mean radiant temperature), the sensible energy need for space heating and cooling, the latent energy need for (de-)humidification, the sensitive and latent design heat load for space heating and cooling and the conditions of the supply air to guarantee any humidification and / or dehumidification.

The calculations are performed separately for the different thermal zones, which can be either coupled or not.

The simplified method is based on the hourly resolution of the air energy balance, accordingly to the assumptions reported in the EN ISO 15217-1 technical standard [15], e.g. the uniformity of the air temperature the thermal zone (or room), the one-dimensional thermal conduction through the building components (excluding the ground). In addition, some simplifying hypotheses are added in EN ISO 52016-1:

- the thermal zone is assumed as a closed space delimited by building envelope components; 
- the thermo-physical properties of the materials that make up the building envelope components are time-independent. Nevertheless, properties based on components activation are not excluded;

- the external radiant environment (excluding the sky) is at the same temperature as the external air;

- the spatial distribution of solar radiation inside the room is uniform and timeindependent;

- the distribution of mass in each construction component is simplified ( 5 different mass distribution classes are presented in the standard);

- the solar properties of the windows do not depend on the angle of incidence of solar radiation;

- the total solar energy transmittance is assumed to be direct transmittance into the zone;

- the mean radiant temperature is calculated as the weighted average over the area of the internal surface of each component.

As for the thermal energy balance of the zone(s), the method reported in the standard is a review of the three-node method (5RC1), already present in EN ISO 13790 [2]. The main difference is that the construction elements are not aggregated to the concentrated parameters zone, instead they are considered separately. In this regard Fig. 1, represents the model with concentrated parameters of a generic component of the envelope.

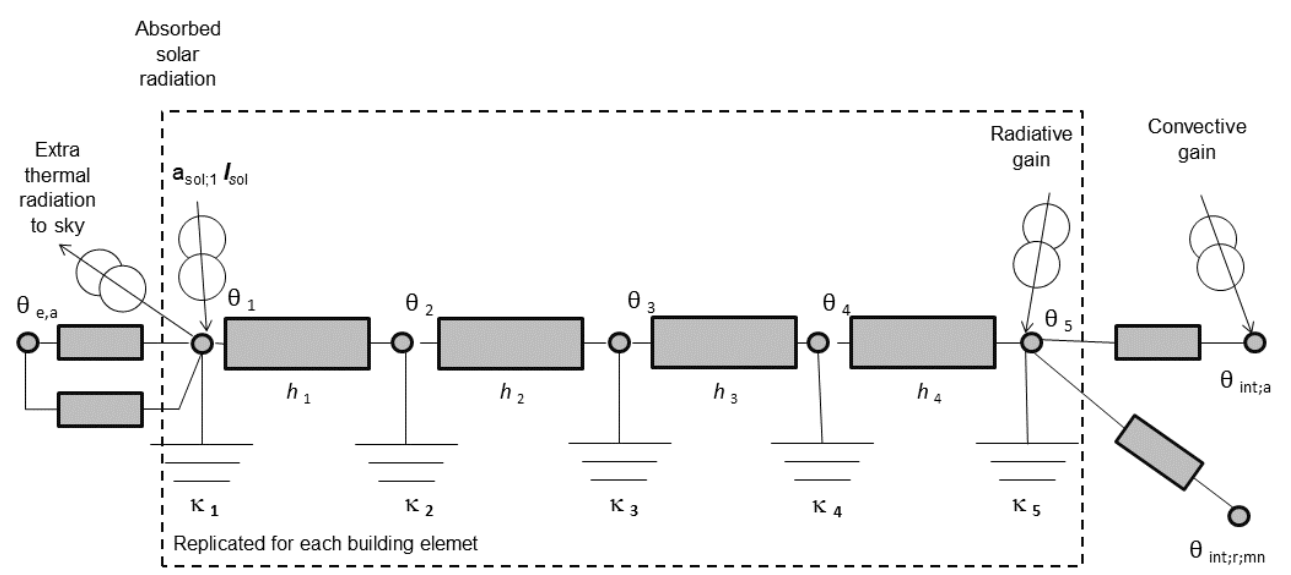

Fig. 1. Illustration of the equivalent "RC" model for a building opaque element.

\subsection{Sensitivity analysis}

The sensitivity analysis is based on a preliminary phase, in which the most influencing input parameters are identified. In particular, the analysis consists in the variation of these parameters and in the numerical evaluation of their influence on the energy need and thermal loads for space heating and cooling, applying both the standard and the tailored ratings.

The most influencing parameters identified and subject to the sensitivity analysis are the occupancy density, the mass distribution in the external walls, the indoor operative temperature set-points during the occupied hours (both in the heating and in the cooling seasons) and the solar transmittance of windows. 


\subsubsection{Mass distribution}

Although most of the chosen input parameters can be easily numerically measured, and therefore a clear application in the sensitivity analysis procedure is possible, the measure of the mass distribution variation needs to be developed. On this matter, a specific parameter, namely the structure deviation, aimed to describe how the mass distribution differs from the actual component, was created.

In this regard, both the actual structure and the 5 different mass distribution classes are described in $x-y$ chart, in which the $x$ - and the $y$-axis represent respectively the structure thermal resistance and areal heat capacity (an example is presented in Fig. 2); the latter is described as a function of the first one through the thermal effusivity, as described in the following equations:

$$
\begin{gathered}
\mathrm{d} k=\rho \cdot c \cdot d s=e^{2} \cdot \mathrm{d} R \\
\mathrm{~d} R=\mathrm{d} s / \lambda \\
e=(\rho \cdot c \cdot \lambda)^{1 / 2}
\end{gathered}
$$

Where $k$ is the areal heat capacity from the external surface to a given depth $\left(\mathrm{kJ} \cdot \mathrm{m}^{-2} \cdot \mathrm{K}^{-1}\right)$, $R$ is the thermal resistance from the external surface to a given depth $\left(\mathrm{m}^{2} \cdot \mathrm{K}^{-} \mathrm{W}^{-1}\right), \rho$ is the mass density $\left(\mathrm{kg} \cdot \mathrm{m}^{-3}\right), c$ is the specific thermal capacity $\left(\mathrm{J} \cdot \mathrm{kg}^{-1} \cdot \mathrm{K}^{-1}\right), s$ is the depth from the external surface $(\mathrm{m}), \lambda$ is the thermal conductivity $\left(\mathrm{W} \cdot \mathrm{m}^{-1} \cdot \mathrm{K}^{-1}\right)$, and $e$ is the thermal effusivity $\left(\mathrm{J} \cdot \mathrm{s}^{-1 / 2} \cdot \mathrm{m}^{-2} \cdot \mathrm{K}^{-1}\right)$.

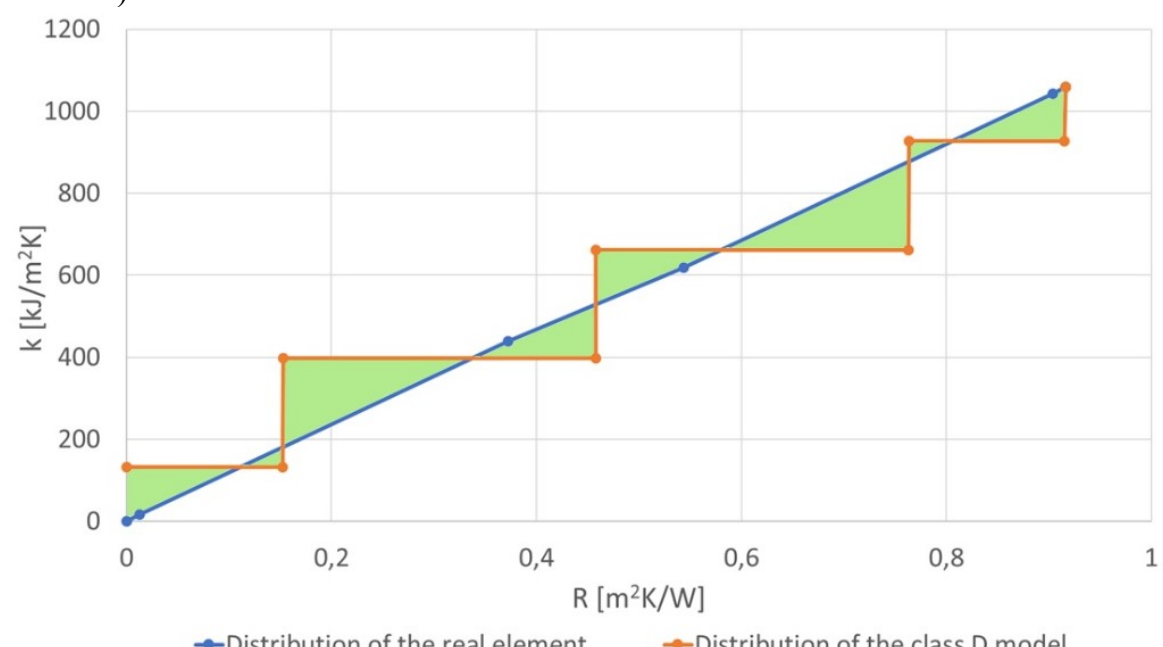

Fig. 2. R-k graph for the external wall actual structure and the EN ISO 52016-1 class D (equally distributed) model.

The parameter ( $\left.\tau_{\mathrm{dev}}\right)$ describing the mass deviation between the actual wall and its model (represented in green in Fig. 2) is described as follows:

$$
\tau_{d e v}=\int_{0}^{R} e^{2}\left|R-R_{\text {mod }}\right| d R
$$

This procedure is reiterated for the five models presented in EN ISO 52016-1. 


\subsubsection{Sensitivity indexes}

The variations of the input parameter are then implemented one at a time in the case study energy models, and their influences on the heating and cooling energy needs and thermal loads are evaluated by means of a sensitivity index $(s)$ calculated as follows:

$$
\begin{gathered}
s=\frac{\operatorname{RMSE}_{\mathrm{O}} / O_{\text {range }}}{\mathrm{RMSE}_{\mathrm{I}} / I_{\text {range }}} \\
R M S E_{O}=\sqrt{\frac{\sum_{\mathrm{i}}\left(O_{i}-O_{0}\right)^{2}}{n}} \\
R M S E_{I}=\sqrt{\frac{\sum_{\mathrm{i}}\left(I_{i}-I_{0}\right)^{2}}{n}} \\
O_{\text {range }}=O_{\text {max }}-O_{\text {min }} \\
I_{\text {range }}=I_{\text {max }}-I_{\text {min }}
\end{gathered}
$$

where $R M S E$ o and $R M S E_{\mathrm{I}}$ represent the root mean squared error (RMSE) of the output and the input, respectively, as defined in Equations 6 and 7, $O_{\text {range }}$ is the output range, as defined in Equation 8, Irange is the input range, as defined in Equation 9, the subscript $i$ and $o$ represent respectively the calculated and the base input and output values, $n$ is the number of the cases considered. $I_{\min }$ and $I_{\max }$ are respectively the minimum and the maximum input values; $O_{\min }$ and $O_{\max }$ are the minimum and the maximum output values, respectively.

\subsection{Case study}

The analysed case study is a residential multi-apartment building located in Rome (Italy, climatic zone D), characterized by a trapezoidal shape (Fig. 3). The building is sited in an urban environment characterized by buildings of equal or lower heights then the case study, which is therefore not particularly shaded by the surrounding buildings.
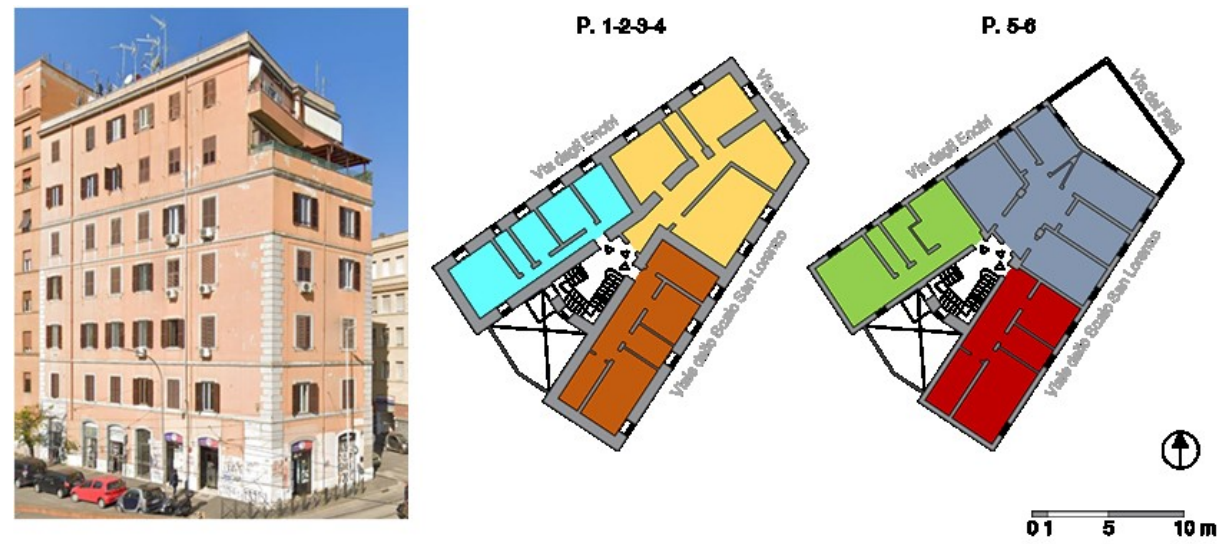

Fig. 3. Building picture and floor plans

The analysed building consists of 7 stories above ground and a basement story, for a conditioned net floor area of $1091 \mathrm{~m}^{2}$. The ground floor, not subject to the present analysis, includes commercial spaces and a condominium room; the other stories above ground are 
instead characterized by 3 apartments each and common stairwell spaces. Moreover, the building is adjacent to another residential building on the South-West façade.

The building was built in 1926 and is characterized by a load-bearing brick and stone wall structure and a mainly uninsulated building envelope. The envelope component thermal properties were evaluated on the basis of the available data provided by an energy audit technical report. The external walls of the intermediate stories are characterized by $70 \mathrm{~cm}$ thickness and are made of two rows of solid bricks separated by a layer of pebbles and crushed stones. The external walls of the $6^{\text {th }}$ and $7^{\text {th }}$ floors are instead thinner $(33 \mathrm{~cm})$ and are characterized by two rows of half-filled bricks separated by an unventilated air gap. The thermal transmittances of the walls of the intermediate stories and of the 6th and 7 th stories are $0.90 \mathrm{~W} \cdot \mathrm{m}^{-2} \mathrm{~K}^{-1}$ and $1.14 \mathrm{~W} \cdot \mathrm{m}^{-2} \mathrm{~K}^{-1}$, respectively.

As for the horizontal opaque components, the floor separating the ground to the first floor is a hollow brick and concrete slab and it is characterized by a thermal transmittance equal to $1.66 \mathrm{~W} \cdot \mathrm{m}^{-2} \mathrm{~K}^{-1}$; the $\mathrm{U}$-value of the flat roof is instead equal to $1.66 \mathrm{~W} \cdot \mathrm{m}^{-2} \mathrm{~K}^{-1}$.

The transparent envelope is characterized by single glazing with metal frame windows at the intermediated stories and by double-glazing with wooden frame windows at the $6^{\text {th }}$ and $7^{\text {th }}$ stories. The thermal transmittance of the windows ranges from 6 to $3 \mathrm{~W} \cdot \mathrm{m}^{-2} \mathrm{~K}^{-1}$.

The apartments are supplied by a centralized heating system, while the stairwell is not heated. The heat emitters are radiators located on the external walls, and the distribution system is characterized by uninsulated pipes running on the internal side of the external walls. No control systems are installed.

\subsection{Calculation assumptions and boundary conditions for simulations}

The climatic data used for the energy performance evaluations refer to the typical climatic year on an hourly basis, elaborated by the Italian Thermo-technical Committee (CTI).

The building has been divided into the following thermal zones:

- $\quad$ thermal zone 1: $2^{\text {nd }}$ floor;

- $\quad$ thermal zone 2 : from the $3^{\text {rd }}$ to the $5^{\text {th }}$ floor;

- thermal zone 3 : from the $6^{\text {th }}$ to the $7^{\text {th }}$ floor.

Table 1. Summary table of user data.

\begin{tabular}{|c|c|}
\hline Parameter & Value \\
\hline Number of people per floor & 7 \\
\hline Total heat power released by a person in $[\mathrm{W}]$ & 118 \\
\hline Convective heat power released by a person in $[\mathrm{W}]$ & 41 \\
\hline Radiative heat power released by a person in $[\mathrm{W}]$ & 39 \\
\hline Latent heat power released by a person in $[\mathrm{W}]$ & 38 \\
\hline Moisture produced by a person in $\left[\mathrm{g} \cdot \mathrm{h}^{-1}\right]$ & 54.7 \\
\hline Mean lighting and appliance heat gains $\left[\mathrm{W} \cdot \mathrm{m}^{-2}\right]$ & 3.01 \\
\hline Mean appliance moisture production in $\left[\mathrm{g} \cdot \mathrm{h}^{-1} \cdot \mathrm{m}^{-2}\right]$ & 0.54 \\
\hline Supply air flow rates $\left[\mathrm{m}^{-3} \cdot \mathrm{h}^{-1} \cdot \mathrm{m}^{-2}\right]$ & 0.2 \\
\hline$T_{\mathrm{op}}$ in occupied hours for heating $\left[{ }^{\circ} \mathrm{C}\right]$ & 20 \\
\hline$T_{\mathrm{op}}$ in occupied hours for cooling $\left[{ }^{\circ} \mathrm{C}\right]$ & 26 \\
\hline Minimum $T_{\mathrm{op}}$ in unoccupied hours $\left[{ }^{\circ} \mathrm{C}\right]$ & 16 \\
\hline Maximum $T_{\mathrm{op}}$ in unoccupied hours $\left[{ }^{\circ} \mathrm{C}\right]$ & 32 \\
\hline
\end{tabular}


The ground floor (not subject to analysis) and adjacent buildings were assumed to be conditioned at constant temperature. The user behaviour data were mainly obtained from UNI EN 16798-1:2019 [16] standard National Appendix draft. Table 1 shows user data assumed in the calculation.

As far as the sensitivity analysis is concerned, the results of the applied procedure to calculate the structure deviation parameter $\left(\tau_{\mathrm{dev}}\right)$ for the 5 mass distribution classes are presented in Table 2. All the chosen input parameters, their base value and the defined variations are instead presented in Table 3.

Table 2. $\tau_{\text {dev }}$ calculation results.

\begin{tabular}{|c|c|c|}
\hline Class & Description & Value [s] \\
\hline Class I & Mass concentrated at internal side & 485 \\
\hline Class E & Mass concentrated at external side & 487 \\
\hline Class IE & Mass divided over internal and external side & 248 \\
\hline Class D & Mass equally distributed & 77 \\
\hline Class M & Mass concentrated inside & 240 \\
\hline
\end{tabular}

Table 3. Parameters of sensitivity analysis.

\begin{tabular}{|c|c|c|c|}
\hline Parameter & Symbol & Base value & Variation \\
\hline Occupant density & $O_{\mathrm{d}}$ & As defined in Table 1 & $\pm 10 \% ; \pm 20 \%$ \\
\hline Mass distribution of external walls $[\mathrm{s}]$ & $\tau_{\mathrm{dev}}$ & 77 & $240 ; 248 ; 485 ; 487$ \\
\hline$T_{\text {op }}$ in occupied hours for heating $\left[{ }^{\circ} \mathrm{C}\right]$ & $T_{\text {set, }}$ & 20 & $\pm 1 ; \pm 2$ \\
\hline$T_{\text {op }}$ in occupied hours for cooling $\left[{ }^{\circ} \mathrm{C}\right]$ & $T_{\text {set, } \mathrm{C}}$ & 26 & $\pm 1 ; \pm 2$ \\
\hline Solar transmittance & $g_{\mathrm{gl}}$ & 0.750 & $0.670 ; 0.850$ \\
\hline
\end{tabular}

\section{Results}

The results of the sensitivity analysis are presented in Figs. 4 and 5, in terms of sensitivity index obtained for the energy needs for heating and cooling for both the standard and the tailored ratings. Fig. 4 highlights the operative temperature set-point as the main parameter that most influences the output results for the heating season. In fact, the sensitivity index for the heating set-point temperature results to be $591 \%$ and $1136 \%$ higher than the other parameters for the tailored and standard rating respectively. In Fig. 5, which shows the results for the cooling season, all the parameters present almost the same relevance, with a slight predominance of the temperature set-point.

The case study, thanks to a quite massive envelope, has a very good response to temperature fluctuations. Evidence of this result can be found in the small variation that heating and cooling energy needs present in standard and tailored rating simulations; due to this latter, the sensitivity results for the two ratings have the same trend for the heating period, and almost the same results for the cooling one. 


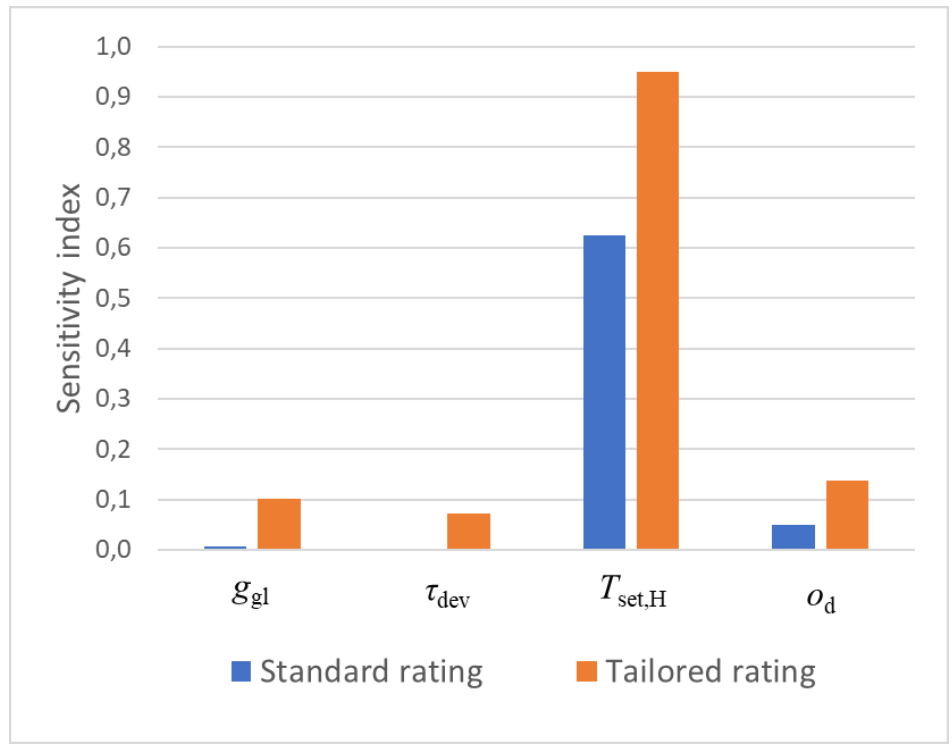

Fig. 4. Sensitivity index for energy needs for heating.

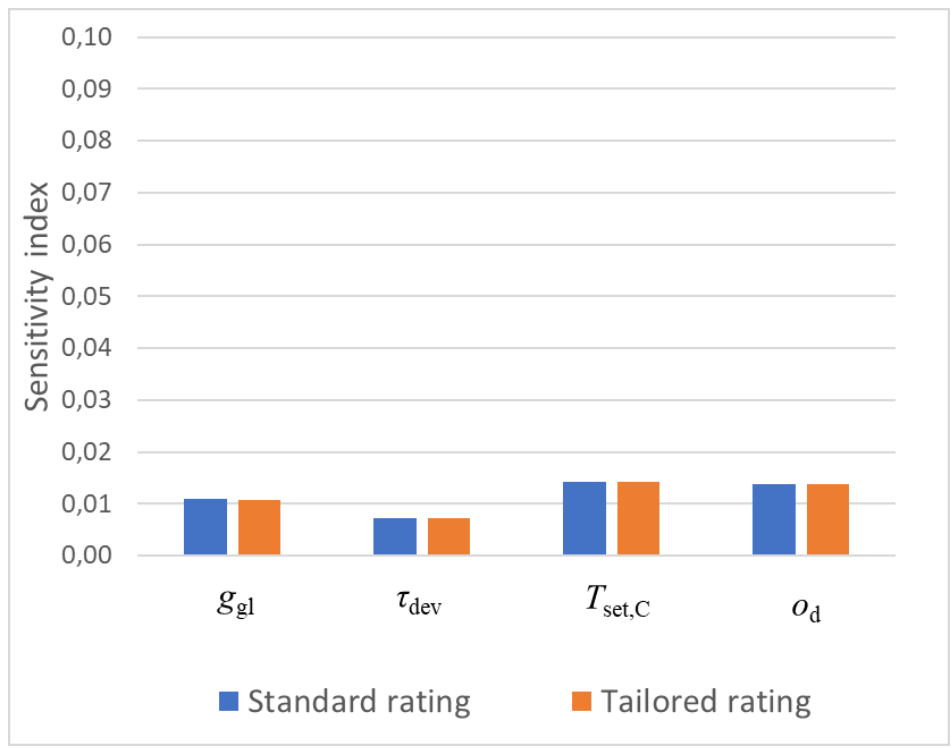

Fig. 5. Sensitivity index for energy needs for cooling.

The sensitivity analysis results for the heating and cooling loads are presented respectively in Figs. 6 and 7.

Generally, the heating and cooling loads result to be much more influenced by the input parameters variations compared to the heating and cooling needs results.

Regarding the heating period, most influencing parameters are the set-point temperature and the occupant density respectively for the standard and the tailored rating. Instead, the results for the cooling season show the same trend for both the standard and the tailored rating, with a light predominance of the occupant density, followed by the set point 
temperature. The other two parameters, as for the heating season, results to be of minor importance.

As regards the building envelope mass distribution, this has a different influence over the heating and cooling loads compared to the energy needs. In fact, differences between the two ratings can be highlighted, especially for the heating period. However, the mass distribution variation results to be the less influencing parameter for both the standard and tailored ratings.

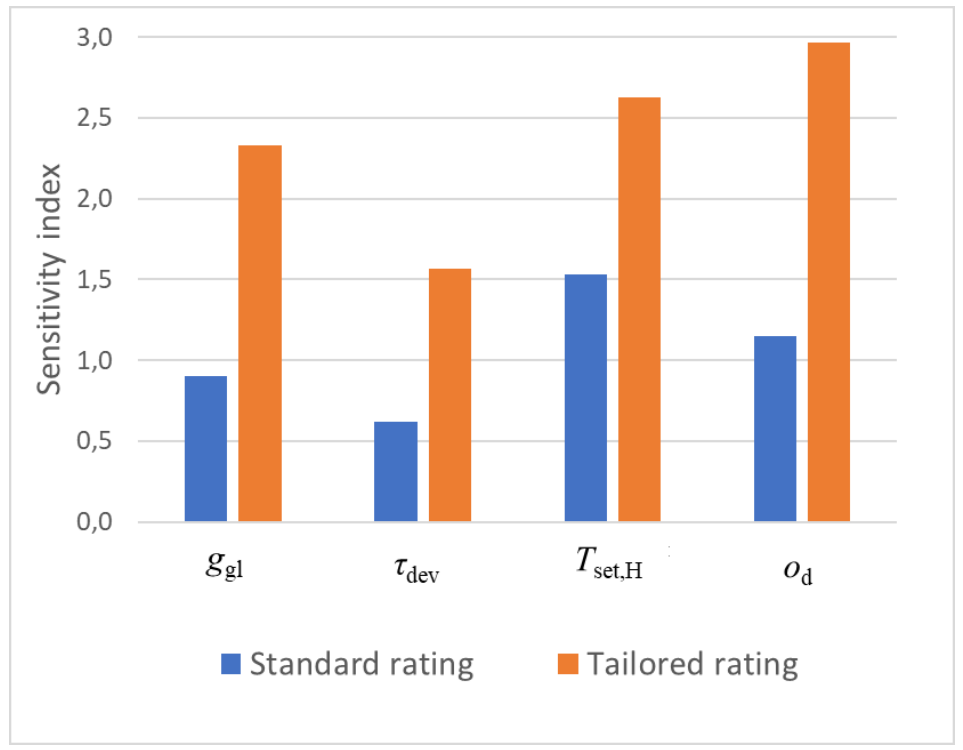

Fig. 6. Sensitivity index for heating loads.

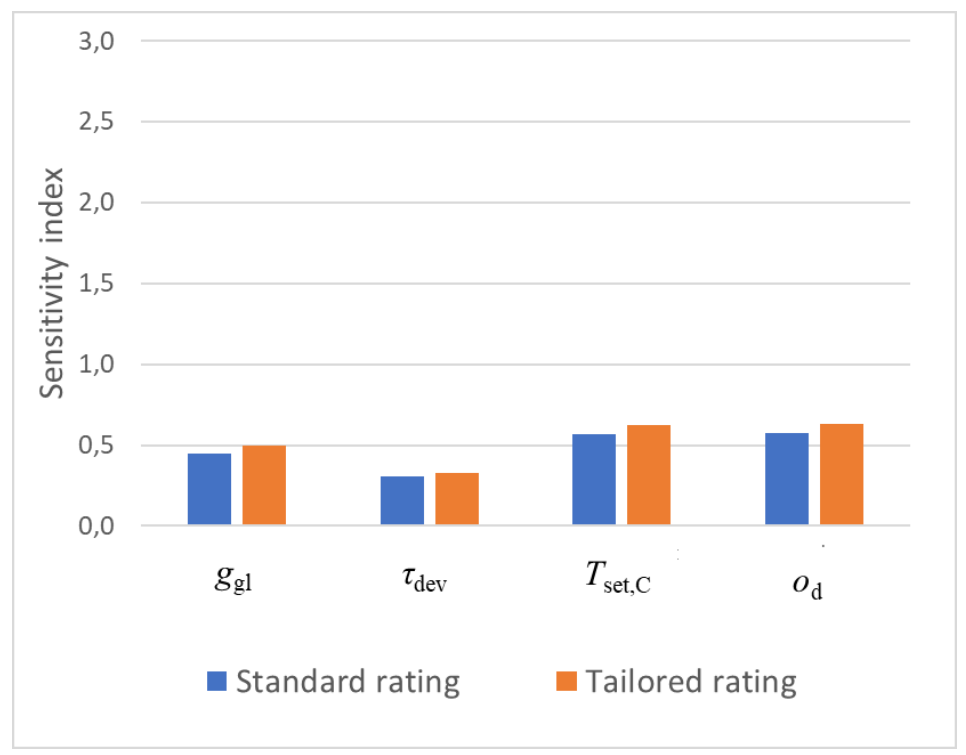

Fig. 7. Sensitivity index for cooling loads. 


\section{Conclusions}

A one-at-a-time sensitivity analysis was performed over the EN ISO 52016-1 simplified dynamic calculation model in order to analyse the influence of the solar transmittance of windows, the indoor operative temperature set-points, the model of mass distribution in building components and the occupancy density over the heating and cooling needs and loads. This preliminary analysis pays the way to develop a wider research activity aimed at validating the EN ISO 52016-1 dynamic method, as to increase its accuracy for the estimation of the building thermal behaviour.

The results of the analysis showed the absolute importance of operative temperature setpoint as the main influencing parameter, among those concerned in the sensitivity analysis, for both the energy needs. Moreover, a strong relevance of the other three parameters, and the occupancy density first, has been highlighted in the cooling period. On the other hand, as regards the heating and cooling loads the main influencing input parameters turn out to be the occupant density and again the set-point temperature.

These results underline that the correct definition of set-point temperatures is the main way to modify and correct an excessive energy consumption. Regarding the loads, while the occupant density is the most important, it is not directly defined in the building design process. For this reason, the other three parameters, which are directly determined by the building designer and have the same order of magnitude, should be carefully defined in order to correctly size the heating and cooling system.

The analysis over the distribution of the mass in the construction, shows that the way the mass model describes the distribution of thermal properties inside the component, does not lead to particularly significant variation of the outputs. This can be traced back to either a problem in the EN ISO 52016-1 model, too simplified to fully describe the phenomenon, or to the case-study characteristics, which flatten the output results differences.

Further works will be focused on the analysis of other building typologies with different building envelope features, and occupancy as well, in order to obtain a wider sensitivity database, independent on the peculiarity of the single case study. Moreover, a deepening in the knowledge over the input parameters will be performed through uncertainty analysis in order also to fully understand how errors in the input definition may alter the results. It will also be of interest to analyse the way the EN ISO 52016-1 calculation methodology examines the different physical phenomenon that play a role in energy balance equation, deepening the way the chosen simplification and the calculation process leads to discrepancies from detailed dynamic simulation models.

This work was based on a research supported by the Italian National Agency for New Technologies, Energy and Sustainable Economic Development (ENEA), regarding the theoretical study of the simplified hourly calculation model and the application to residential housing.

\section{References}

1. EN ISO 52016-1. Energy performance of buildings - Energy needs for heating and cooling, internal temperatures and sensible and latent heat loads - Part 1: Calculation procedures. (2017)

2. EN ISO 13790. Energy performance of buildings - Calculation of energy use for space heating and cooling (ISO 13790:2008) 
3. I. Ballarini, E. Primo, V. Corrado, "On the limits of the quasi-steady-state method to predict the energy performance of low-energy buildings", Thermal Science, 22 (2018), S1117-S1127.

4. J. Jokisalo, J. Kurnitski, , Performance of EN ISO 13790 utilisation factor heat demand calculation method in a cold climate, Energy and Buildings, 39 (2007), pp. 236-247

5. V. Corrado, E. Fabrizio, Assessment of building cooling energy need through a quasisteady state model: Simplified correlation for gain-loss mismatch, Energy and Buildings, 39 (2007), pp. 569-579

6. A. Gasparella, G. Pernigotto, Comparison Of Quasi-Steady State And Dynamic Simulation Approaches For The Calculation Of Building Energy Needs: Thermal Losses, Proceedings, International High Performance Buildings Conference, Purdue, In., USA, 2012, paper 88

7. G. Kokogiannakis, P. Strachan, J. Clarke, "Comparison of the simplified methods of the ISO 13790 standard and detailed modelling programs in a regulatory context", Journal of Building Performance Simulation, 1 (2008), 209-219.

8. V. Corrado et al., Verification of the new Ministerial Decree about minimum requirements for the energy performance of buildings, Energy Procedia, 101 (2016), pp. 200-207

9. M. Beccali et al., Simplified models for building cooling energy requirement, Proceedings, 7th International IBPSA Conference, Building Simulation, Rio de Janeiro, Brazil, 2001, pp. 295-302

10. P. Michalak, "The simple hourly method of EN ISO 13790 standard in Matlab/Simulink: A comparative study for the climatic conditions of Poland", Energy, 75 (2014), 568-578.

11. M. Atmaca, E. Kalaycioglu, Z. Yilmaz, "Evaluation of the heating \& cooling energy demand of a case residential building by comparing the national calculation methodology of Turkey and EnergyPlus through thermal capacity calculations", Technical Report, 2011, Energy Systems Laboratory, Texas A\&M University.

12. A. Costantino, I. Ballarini, E. Fabrizio, "Comparison between simplified and detailed methods for the calculation of heating and cooling energy needs of livestock housing: a case study", Proceedings of 3rd IBPSA Conference Italy, 8-10 February 2017, Bolzano (Italia).

13. I. Ballarini, A. Costantino, E. Fabrizio, V. Corrado, "The Dynamic Model of EN ISO 52016-1 for the Energy Assessment of Buildings Compared to Simplified and Detailed Simulation Methods", Proceedings of 16th IBPSA Building Simulation Conference BS2019, 2-4 September 2019, Roma (Italia).

14. V. Siva Kamaraj "Dynamic building modelling using an extensive RC network according to ISO 52016: numerical implementation and testing." (2018).

15. EN ISO 15217-1. Energy performance of buildings - Methods for expressing energy performance and for energy certification of buildings

16. UNI EN ISO 16798-1. Energy performance of buildings - Ventilation for buildings - Part 1: Indoor environmental input parameters for design and assessment of energy performance of buildings addressing indoor air quality, thermal environment, lighting and acoustics - Module M1-6 (2019)

17. EN ISO 52016-2. Energy performance of buildings - Energy needs for heating and cooling, internal temperatures and sensible and latent heat loads - Part 2: Explanation and justification of ISO 52016-1 and ISO 52017-1. (2017) 
18. A. Angelotti, M. Ballabio, L. Mazzarella, C. Cornaro, G. Parente, F. Frasca, A. Prada, P. Baggio, I. Ballarini, G. De Luca, V. Corrado, "Dynamic simulation of existing buildings: considerations on the model calibration", proceedings from BS2019 16th Int. Building Simulation Conference. Roma, Italy (2019) 